\title{
La Crisis Social de Nuestro Tiempo y la Doctrina Social de la Iglesia
}

\author{
Por el Doctor LUIS ECHECOPAR GARCIA (1)
}

El tema de mi conferencia es la crisis social de nuestro tiempo y la doctrina social de la Iglesia.

Debo confesar çuo, después de haberlo escogido, me he sentido abrumado por mi propio audacia.

No soy sociólogo, ni economista, ni en forma alguna versado en teología. ¿Porqué habría, pues, de ocuparme yo, simple abogado, de asun. to tan complejo que exige ser perito en todas estas materias y sobre el cual se han escrito volúmenes enteros?

Sin duda esta simplísima pregunta pudo obligarme a dejar el tema: pezo ha hábido aigo quie me ha reafirmado en la decisión de tratarlo.

Si no soy un experto, tengo sí profunda inquietud por los problemas que encierra y el deseo de lleger al fondo de los mismos. Son en la actualizad los más dignos de esiudio, puesto que afectan ya en grado sumo nuestras vidas y también a nuestras familias $y$ pueden pesar en forma definitiva sobre las futuras generaciones.

Por lo mismo, considero que debe trasmitirse esta inquietud $\mathrm{y}$ el afán de estudiarios, porque sólo en tal forma $Y$ para el bien general podremos encontrar las soluciones anheladas. Hay también en ello un deber de caridad para con nuestros semejantes y una obligación moral en relación con la comunidad social en que vivimos. Los pensadores eminentes nos dan sin duda las grandes ideas y las normas-guias; pero somos los hombres comunes quienes debemos practicarlas.

No cabe duda de que vivimos en medio de una de las más grandes conmociones sociales de la historia. Después de las dos tremendas guerras que asolaron la tierra en la primera parte de este siglo, Oriente y Occidente viven una contienda fría, sorda e implacable. A diario se cierne sobre el mundo entero la amenaza de una guerra nuclear, del exterminio

(1) Catedrático Emérito y ex-Decano de la Facultad de Derecho y Ciencias Políticas de la Pontificia Universidad Católica; ex-Ministro de Hacienda y Comercio.

Conferencia dictada en la Universidad Peruana de Ciencias Médicas y Biológicas, Cayetano Heredia. 24-10-63. 
total de vidas y ciudades. En el seno de las naciones reina la incertidumbre y la desesperanza.

Alemania sigue dolorosamente dividida después de más de quince años de la terminación de la última guerra. La Europa Central no recobra aún su libertad.

En España sólo el recuerdo de los indecibles sufrimientos padecidos durante la última guerra civil impide que surja de nuevo la contienda. En. Francia $y$ en Portugal la incognita sobre el porvenir político-social es cada vez más incierta a medida que se acerca el fin de los períodos de los actuales gobernantes. Oriente vive la amenaza del crecimiento y desbordo de la China. Los pueblos de Africa salidos del colonialismo no logran aún. encontrarse a sí mismos. En Ámérica del Norte arrecia la lucha de razas. En nuestra América del Sur, la Argentina encuentra cada vez más difícil superar sus dificultades. El Brasil lucha entre el desempleo, la inflación y el clamor por una vida más ordenada. En Venezuela los choques de fac. ciones son cada vez más agudos. Colombia no logra aún poner fin al bandolerismo, síntoma evidente del desconcierto social. Cuba vive la ominosa pesudilla del régimen castrista. Entre nosotros, los políticos hablan cada vez con más frecuencia de la necesidad de una revolución social o económica.

Síntomas son todos éstos de una grave crisis; pero no de una simple crisis cíclica, de exceso de producción o de sub-consumo, de la cual puedan reestablecerse prontamente las naciones mediante simples reajustes económicos, sino de algo muchísimo más grave. ¿Estamos acaso en un momento semejante a aquel que precedió a la caída del Imperio Romano - a la Revolución Francesa? o ¿Es simplemente que, siguiendo los principios de Spengler, el mundo vive la decadencia de Occidente y la calma no volverá a reinar hasta que surja una nueva Cultura?

Röepike afirma (1) que. simplemente, hemos agotado las reservas culturales del siglo pasado y cita a Renán que dijera que "vivimos del perfume de un trasco vacío".

Sólo examinando los síntomas de la crisis podrá llegarse a calificarla. Son éstos según el mismo Röepke de dos clases; de tipo moral- espiritual; y de tipo sociológico o mejor dicho socio-económico.

Ei lo moral-espiritual, sostiene que predominan hoy la arbitrariedad y el carácter discrecional de los puntos de vista, la pérdida general del estilo, la degeneración de la ortografía motivada por la falta de respelo a la lengua, la decadencia de la facultad de expresión viva, "el destierro del hombre fuera del arte". la emocionalización, por no decir la sexualizasión. de la música desde que terminó el llamado período clásico. El relativismo $Y$ el agnosticismo científico.

Dentro de este proceso de decadencia, dice, se ha producido el abandono de las certidumbres esenciales, el relativismo ilimitado, el agotamien-

(1) Wilbelm Roepke, la "Crisis Social de Nuestro Tiempo". Ed. Revista de Occidente, Madrid 1956, p. 10 y sgtes. 
to progresivo de un patrimonio heredado; y como consecuencia "el hombre ha ido perdiendo paralelamente su seguridad instintiva natural, su criterio para apreciar lo idóneo en la naturaleza humana hasta el punto de que su relación con las cosas más elementales - con el trabajo y el descanso, con la naturaleza, con el tiempo y la muerte, con el sexo contrario, con el hijo y $l x$ descendencia, con la juventud y la ancianidad, con el goce natural de la vida, con lo numular, lo ultraterreno, con la propiedad, con la guerra y la paz, con la razón, el sentimiento y la comunidad - ha quedado gravemente trastornada. Han olvidado casi por completo esa medida de las cosas que hay en el hombre mismo, y oscilan ahora de un extremo a otro, ensayando tan pronto eso como aquello, aceptando una $u$ otra opinión de moda, siguiendo unas $u$ otras atracciones externas, pero sin escuchar apenas la propia voz, sin oir las razones del fuero interno".

"De esta forma - concluye - se produjo un vacío, con razón sentido insoportable, que acabó por ser rellenado con seudo ciencia y con seudo política.".

En el aspecto socio-económico hace notar el mismo Röepke que, lejos de mantenerse estructuras auténticas, con gradaciones intermedias, con jerarquías debidamente establecidas, en las que predominen la capacidad y los dotes de mando y las colectividades rodeadas de calor humano, se ha producido un proceso de desmenuzamiento $y$ de apelotonamiento que destruye la estructura social y al que se ha llamado "masificación", esto es un proceso colectivo en que la sociedad se ha disgregado en montones de individuos abstractos, solitarios y aislados en cuanto hombres, pero apiñados en cuanto son portadores de una función social; proceso en que los hombres se encuentran en la más estrecha y anónima relación de tipo material y mecánico con la totalidad de los demás conciudadanos en la calidad de compradores y vendedores, como radioescuchas y espectadores de cine, como pensionistas, como beneficiarios de seguros sociales o de cualquier otro tipo de organización centralizada, etc.; pero en el que se ballan aislados y desconcerta pues, faltan los lazos de la proximidad, de la espontaneicad de su origen y del calor de las relaciones humanas directas.

Indica, así mismo, que las condiciones sociológicas que favorecen esta masificación son tres:

a).--La demográfica, constituída por el aumento descomunal de la población;

b).-La técnica, constituída por la proletarización de una mayor o menor parte de la población, o sea por la reducción de ésta a una situación sociológica y antropológica caracterizada por la dependencia económica social, por la falta de arraigo, por la vida al estilo cuartel, por el alejamiento de la naturaleza y por la carencia de propiedad, y por falta de atractivo en el trabajo, debidos a la moderna técnica de la máquina, al modo de emplearla, a ciertas formas de organización de empresas industriales y a determinadas medidas político sociales del Estado, que condenon a millones de seres a llevar una vida que no les permite desenvolverse positivamente como hombres ni como ciudadanos; $y$ 
c).-La político-social-institucional, caracterizada por la decadencia de la familia reducida hoy en muchos casos a una simple comunidad de consumo, por el aniquilamiento de la vida rural en comunidad; por la decadencia de los pueblos en favor de la ciudad; por la crisis de la democracia; por la merma de la autoridad, de la imparcialidad y de la unidad del Estado; por el crecimiento del centralismo y de la burocracia; y por el desarrollo de tendencias precolectivas 0 en algunos casos por la franca implantación del colectivismo o del socialismo no como superación de la crisis de la democracia sino como la última y más grave consecuencia de la enfermedad que afecta a la moderna sociedad de masas, ya que agrava hasta el máximo el mal número uno de nuestro tiempo, a saber: la "masificación" y proletarización que conduce a un despótico estado de masas.

Concluye también que a la seudo integración de la sociedad corresponde paralelamente el seudo gobierno, es decir, la dominación del Estacio, la cultura y la sociedad por hombres sin títulos legítimos para el ejercicio de la auténtica dirección espiritual.

Dentro de este cuadro, Röepke hace notar especialmente que el sistema económico europeo-americano "capitalista", caracterizado históricamente por la propiedad privada de los bienes, tanto de consumo cuando de producción, por la división del trabajo y por la libre compelencia del marcadn, ha evolucionado en muchos países en forma inestable e injusta por el amplio y creciente margen que deja para el enriquecimiento mediante maniobras monopolistas y la política de opresión de grupos de intereses, por el deficiente funcionamiento de muchos mercados particulares, por la proletarización, comercialización, concentración y aglomeración del poder; por exageraciones especulativas y destrucción de capitales; por ser excesivo y antinatural, hasta imponer a los hombres condiciones de vida con. tra las cuales acaban por rebelarse empujados por un vago malestar y por objetivos poco claros.

También advierte que esta rebelión contra el sistema del mundo occidental ha desembocado en el anticapitalismo, con sus múltiples gradaciones que llegan hasta el radicalismo, en el socialismo y en el colectivismo, que él no considera una solución, sino más bien el último extremo hasta donde podemos alejarnos de ella.

Entre nosotros este planteamiento se complica por no existir en el Perú un régimen económico uniforme sino, en reclidad, como bien lo ha dicho Rómulo Ferrero en reciente conferencia, tres situaciones diferentes, pero yuxtapuestas: la economía precapitalista o capitalista de la costa; la eccnomía semi-feudal de la sierra; y la economía primitiva tradicional de la mayoría de las comunidades indígenas.

Es de preguntorse, sin embargo, cómo se explica que, a pesar de no estar plenamente desarrollado en nuestro país ni en otras naciones el sistema capitalista cuya crisis socio-económica describe Röepke, la misma nos ha afectado ya, quien sabe con más intensidad que en los lugares de origen. 
Para mí la respuesta es clara. Hemos adquirido el sistema de las Estados desarrollados, pero no sólo con sus aciertos sino también con sus errores. Por consiguiente, mientras a ellos el mal los ha atacado en la miadurez, ha hecho impacto en nosotros durante la adolescencia y cuando aún no se habían acumulado suficientes reservas $y$ defensas morales, económicas y políticas para hacerle frente con pronto éxito.

Además considero que en todas partes el mal se ha hecho patente debido a la existencia de un mismo denominador común que es el despertar de las masas.

Por la gran extensión de la educación; por la comunicación con ctras personas; por el contacto con otros medios, en virtud de las facilidades que brinda el transporte moderno; por la lectura de los diarios y revistas; $y$ mediante el cine, la radio y la televisión; se ha llevado a la mayoría de los hombres a la certidumbre de su igualdad intrínseca ante la ley y ante la divinidad. Por la comparación con otros niveles de vida ha hecho carne en ella la extensión de los desniveles sociales, de sus sutrimientos, de los desequilibrios económicos y sociales $y$ de todo lo que le hace falta $y$ se le ha suscitado una inquietud $y$, en ciertos casos, podría decirse, un espíritu de rebelión por cambiar tal estado de cosas. Por el desarrollo de la democracia y el fomento de los sindicatos, la masa ha adquirido además conciencia de su poder y de su capacidad para actuar. Así ha sucedido que al poder de la arisiocracia, de la situación social preexistente, de la riqueza o de las élites intelectuales viene a oponerse ahora el poder del gran número.

¿Cuál es la solución para ello? ¿Ha de producirse un choque? ¿Debe destruirse iodo lo anterior? ¿Presenciarán ésta y las futuras generaciones unc lucha hasta lo último por el predominio? ¿Será el socialismo en alguna cie sus formas, inclusive el comunismo, la solución? ¿No hay más solución que una revolución?

Son estas interrogantes las que, en mi concepto, absuelve con éxito la àoctrina social de la Iglesia.

No requiere ella choques, revolución, ni destrucción, sino la observancia de los principios morales y sociales imperecederos de la justicia, del amor al semejante y de la libertad efectiva de todos los pueblos para que reine la paz entre los hombres.

No es ella una teoría más, sino la proyección del dogma y de la moral cristiana en el plano social.

Sus fuentes son, las Sagradas Escrituras, la teología moral, los documentos pontificios y los resultados de la investigación y estudios cotidianos (escritos de los Obispos, libros de divulgación, artículos de revistas, exposiciones y debates de las semanas sociales, etc.).

Como se concreta especialmente en las encíclicas papales, que constituyen la palabra oficial de la Iglesia, vale la pena recordar en sintesis el contenido de las principales.

Ia Rerum Novarum, de SS León XIII, de 15 de Mayo de 1891 y a la que por su extrcoordinaria trascendencia Pío XII calificara como "la Carta 
Magna que debe constituir el fundamento de toda actividad cristiana en el orden social", tuvo por objeto puntualizar la situación mísera y calamitosa sn que vivían los obreros a fines del siglo pasado y encontrarle remedio.

Previendo la lucha de clases dice "no se halla ya cuestión ninguna por grande que sea, que con mayor fuerza que ésta preocupe los ánimos de los hombres".

Condena por igual al socialismo que, después de excitar en los pobres el odio a los ricos, pretende acabar con la propiedad privada para sustituirla por la colectiva, con injusticia y daño aún para los mismos obreros; y al liberalismo del tipo manchesteriano que había sido impotente para solucionar legítimamente la cuestión social.

Proclama netamente la potestad de la Iglesia para dirimir en el asunto: señala normas para la intervención del Estado como guardián del bien común y defensor de los pobres y puntualiza los deberes de los obrerns y de los patronos en materia de justicia, de caridad $Y$ de fraternidad cris. tianas.

Muy en especial insiste en la legitimidad de la propiedad privada, en la necesidad de extender ésía al mayor número; en la obligación imperiosa de mejorar las condiciones del trabajo de hombres, mujeres y niños y de pagar al obrero un justo salario, esto es una remuneración suficiente para atender al obrero, a su mujer y a su familia, aún para que pueda formarse un pequeño capital, $y$ en ningún caso insuficiente para la sustentación del hombre frugal y de buenas costumbres. Recomienda insistentemente la formación de gremios $\mathrm{y}$ asociaciones.

La Quadragésimo Anno de SS Pío XI, fechada en 15 de Mayo de 1931 reatirma estos principios pero tomando en cuenta los cambios ocurridos desde la publicación de la Rerum Novarum.

Señala los derechos y deberes de la Iglesia, precisa algunos puntos de su doctrina social y amplia su ámbito a las nuevas situaciones creadas desde 1891 .

En especial es importante por su definición de carácter social e individual del salario; por su indicación de que es necesario suavizar el contrato de trabajo con elementos del contrato de sociedad; por su conde. $\mathrm{n} x$ del comunismo; por su anatema contra la codicia del predominio comercial e industrial $y$ por su exhortación para que se reinserte el orden moral en el mundo económico $y$ para que se persiga los intereses individuales $y$ sociales en el ámbito del bien común $y$ con espíritu de justicia $y$ de caridad.

También es importante por su recomendación para que se ponga en vigencia una ordenación jurídica, interna o internacional, con un complejo de instituciones estables, tanto públicas como privadas, inspirada en la justicia social y concorde con la economía y el bien común.

La Divini Redemptoris de SS Pío XI de 19 de Marzo de 1937, define más ampliamente la posición de la Iglesia ante el Comunismo y depués de examinarlo en todos sus aspectos lo condena expresamente. Esta misma condera se reitera en el decreto de la Sagrada Congregación del Santo 
Oficio de 30 de Junio cle 1949 que declara que no es lícito cooperar con el comunismo y que los fieles que profesan la doctrina del comunismo materialista y anticristiano y los que lo difunden y propagan incurren, ipsofacto, como apóstatars de la fé, en la excomunión reservada de modo especial a la Sede Apostólica.

La Mater et Magistra de SS Juan XXIII, de 15 de Mayo de 1961, tiene por objeto ampliar las enseñanzas de las anteriores y está orientada a la acción.

Trata, así de la iniciativa personal y de la intervención de los poderes públicos en el campo económico; de la socialización como fenómeno de la época moderna; de la remuneración del trabajo dentro de los criterios de justicia y de equidad; de las exigencias de la justicia frente a las estructuras productoras; de la propiedad privada y pública y de su función social; de las exigencias de justicia entre los sectores productores y entre las naciones en diverso grado de desarrollo económico; y de la reconstrucción de las relaciones de convivencia en la verdad, en la justicia y el amor.

La Pacem in Terris también de SS Juan XXIII, de 11 de Abril de 1963, en fin, trata sobre la forma de implantar la paz en toda la tierra fundada en Ia verdad, en la justicia, en el amor y en la libertad, analizando para ello el orden de los seres humanos, las relaciones del hombre con los poderes públicos y con las comunidades políticas, las relaciones entre éstas y, por último, de todos con la comunidad mundial y señala las normas respectivas de comportamiento y de acción.

Como se verá, el campo cubierto por estas encíclicas es inmenso y muchos puntos de ellas, por sí solos, podrían dar campo para escribir libros enteros.

Cabe mencionar al lado de ellas el discurso de SS Pío XII con motivo ciel cincuentenario de la Encíclica Rerum Novarum; su mensaje de Pentecostés de 1941 y su radio mensaje de Navidad de 1942.

Algunos se han preguntado porqué la Iglesia ha intervenido en estos campos; pero la respuesta es obvia, si se tiene en cuenta que a ella le corresponde formar las conciencias, proyectar el dogma y la moral no sólo en el plano individual sino también en el social, poner en guardia contra el error y el mal y dar directivas de acción según sus principios.

No pretende con ello ser infalible, salvo cuando habla ex-cathedra en esurios de dogma, pero sí definir con su doctrina principios morales imperecederos e impartir enseñanzas con valor para todos los hombres.

No es posible en una conferencia de una hora analizar tan amplia doctrina, que cubre todo el campo económico-social y múltiples relaciones humcna,s, nacionales e internacionales; y por eso he de referirme única$m \in n t e$ en apretada síntesis a sus elementos básicos.

Tres ideas presiden la teoría social de la Iglesia, o sea: la dignidad ide la persona humana, el bien común y el derecho del Estado de actuar como gestor del bien común.

La dignidad de la persona humana significa que el hombre no es un simple animal racional, sino mucho mós que eso. 
Es desde luego una naturaleza con inteligencia y con voluntad libre pero además tiene una dignidad especial por haber sido creado por Dios, por haber sido redimido por Jesucristo, por ser hijo y amigo de Dios y por ser heredero de la gloria eterna.

De esta dignidad nace que tenga derechos y deberes naturales que, según el Pontífice Juan XXIII, son universales, inviolables e inalienables.

Entre tales derechos figuran:

El derecho a la existencia que incluye tanto su integridad física, cuanto un nivel de vida digno, cuanto la previsión o seguridad social para los. casos de infortunio;

El derecho a los valores morales y culturales, como son el respeto a su persona, a su reputación, a la búsqueda de la verdad, a expresar sus ideas, a cultivar el arte, a estar informado $y$, en general, a participar en los bienes de la cultura.

El derecho de honrar a Dios pública y privadamente;

El derecho a elegir su propio estado, que incluye la adopción del ostado matrimonial o del sacerdotal, la formación de la familia, la educa. ción de los hijos، el trabajo y la propiedad privada, tanto de bienes de consumo como de producción;

El derecho de asociación;

El derecho de emigración e inmigración;

El derecho a tomar parte en la vida pública y a contribuir a la consecución del bien común; y

El derecho de defender jurídicamente sus propios derechos.

Entre los deberes que corresponden a su dignidad figuran todos los correlativos a sus derechos.

Consecuencia de su derecho a la vida e integridad es el deber de conservarlas;

Fruto de su naturaleza sociable y de su personalidad dotada de conciencia libre es el deber de mutua colaboración con los demós, la obligación de actuar en forma responsable, respetando derechos y cumpliendo obligaciones, por convicción, por iniciativa propia y no sólo a fuerza de imposiciones:

Corolario de su dignidad es también el deber de vivir con los demás hombres en forma ordenada, propia de su condición de homóre, deponiendo la mentira, comunicando sus conocimientos de luz $y$ de verdad, actuando con justicia, fraternalmente $y$ dentro de un ambiente de libertad y de moralidad.

Ha habido por cierto quien ha negado que estos derechos $y$ obligaciones, emanan de una ley natural, pretendiendo que sólo provienen de la ley positiva; pero lo cierto es que sólo la dignidad del hombre y el carácter natural de la misma son las que impiden que el poderoso abuse del humilde, que lo reduzca a la esclavitud o que lo use como conejillo de Indias: para sus experimentos; que el Estado por decisión de una mayoría dicte 
leyes tiránicas para ejecutarlas tiránicamente; o que una Nación omnipotente avasalle a sus vecinos inermes.

Paralelo a este concepto de la dignidad humana enuncia la Iglesia el del bien común، que es, según SS. Juan XXIII, (Encíclica Pacem in Terris) "el conjunto de condiciones sociales que consienten $\mathrm{Y}$ favorecen en los seres humanos el desarrollo integral de su propia persona".

Este no se determina, según SS. Pío XII (Eincíclica Sumi Pontificatus) por concepciones arbitrarias, ni encuentra su ley primoráial en el descrrollo material de la sociedad "sino en el desarrollo armonioso y en la perfección moral del hombre a que el Creador ha destinado a la sociedad en cuarto medio".

Significan estos conceptos que el hombre no puede actuar egoistamente; que la Iglesia no ampara el individualismo exclusivista; $y$ que claramente reconoce la dignidad del hombre que vive en sociedad, pero no para uno sólo sino para cada uno de ellos, esto es para todos los hombres; pero también signitica que el bien común no está orientada en favor de: la sociedad como una masa informe superior a los hombres que le son anteriores y que la constituyen, sino en beneficio de los individuos que la forman, como hombres dignos, como hijos de Dios. La sociedad resulta. asi el medio de la perfección, el medio para ejercitar el bien común pero no el fin del bien común.

Por eso, se considera realizado el bien común, dice SS. Juan XXIII, (Enciclica Pacem in Terris), cuando se han salvado los derechos y los deberes de la persona humana; cuando se reconocen; respetan, armonizan, tutelan y promueven aquellos derechos y cuando se contribuye $\alpha$ hacer más fácil el cumplimiento de los respectivos deberes.

Rector del bien común en concepto de la Ílesia, es el Estado; y, por lo mismo, no debe limitarse a actuar como simple vigilante. Ha de respeiar, sin duda, la iniciativa personal de particulares o de grupos y no le corresponde sustituirlos donde son capaces; pero le toca adoptar un papel positivo para evitar y sancionar el mal, para reducir los desequilibrios, para linitar las oscilaciones, para descartar la desocupación $y$ asegurar el pleno empleo y, en general, para perseguir el desarrollo armonioso y la perfección. moral de sus súbditos.

Esto se puede lograr, según SS. Juan XXIII (Encíclica Pacem in Terris), mediante la armoniosa composición $y$ eficaz tutela por acción del Estado. de los derechos y deberes con que unos hombres están vinculados a otros en la sociedad y mediante la promoción de los derechos de la persona; creando un ambiente adecuado en el que a todos los miembros del cuerpo socill se les haga posible $y$ se les facilite el efectivo ejercicio de los derechos mencionados, velando para que el desarrollo de la economía corresponda al progreso social, estableciendo equilibrio entre las diversas formas de intervención del Estado, cuidando de la perfección de la estructura y del funcionamiento de los poderes públicos, de acuerdo con las situaciones históricas de las respectivas comunidades políticas, haciendo que la ordenación jurídica corresponda al grado de madurez de la comunidad política ${ }_{r}$ de modo que se amolde a la realidad, dando participación a todos los: 
ciudadanos en la vida pública, siempre de acuerdo con el grado de madurez de cada Comunidad; $y$, en fin, actuando en forma tal que no haya privilegios y que no se impida a cada cual el pleno ejercicio de sus derechos, ni se sofoque la libertad privada.

A este respecto, el correcto equilibrio entre la intervención del Estado y los derechos y actuación del individuo fué perfectamente delineado por SS. Pío XII que, en una comunicación al Congreso Nacional de la UCID, ,en Roma, en Agosto de 1957, dijera lo siguiente:

"El Estado tiene su propia función en el ordenamiento de la ccnvivencix social. Para llenar tal función debe ser fuerte y tener autoridad. Pero aquellor que lo invocan contínuamente y le atribuyen toda la responsabilidad, lo conducen a la ruina y no hxcen sino el juego de poderosos grupos interesados. La conclusión es que así viene a terminar cual zuier responsabilidad personal en la cosa pública y que cuando alguno habla de deberes o negligencia del Estado, quiere decir deberes o faltas de grupos cnónimos entre los cuales naturalmente no cree encontrarse".

"Todos los ciudadanos deben conocer que el Estado, cuya intervención solicitan, concretamente $y$ en último análisis, es siempre la colectividad de los ciudadanos mismos, y que nadie puede pretender que el Estado tenga obligación o carga a cuya ejecución él mismo no esté resuelto a contribuir con la conciencia de la responsabilidad que, en uso del derecho, le haya sido acordada por la ley".

El mismo Pontífice, en su Radio Mensaje de Navidad de 1944 establece en hermosa forma la posición de cada cual dentro del cuadro que acaba de dibujarse.

"La dignidad del hombre, dice, es la dignidad de la imagen de Dios; la del Estado es la dignidad de la comunidad moral querida por Dios; la de la autoridad política es la dignidad de su participación en la autoridad do Dios".

Las relaciones entre los hombres y el Estado, en la prosecución del bien común deben realizarse, según ya se ha dicho anteriormente, dentro de un concepto de verdad, de justicia, de amor tratemo y de libertad.

De elios resulta, igualmente, la solución de la Iglesia a los diversos problemas que embargan a los pueblos modernos, en relación con la organización de la sociedad y del Estado; y con la propiedad, los salarios, el trabajo, la remuneración, el sindicalismo y la solución de los conflictos so. ciales.

Tratándose de la organización integral de la sociedad, la Iglesia no fija un patrón determinado. Más bien señala normas. Indica lo que a su juicio es malo y aconseja poner en prácicica lo que juzga bueno. Dentro de esos cauces hay ancho espacio para regular o construir la sociedad en cadu lugar de acuerdo con la madurez de la respectiva comunidad política.

Así condena al socialismo en sus diversas formas: en las extremas, por ser enemigas de la autoridad política, de toda propiedad privada, de todo orden social y profundamente anti-religiosas; y, en sus fases más moderadas, por contener siempre elementos de ateismo $y$ de capitalismo de Estado y de absorción total del individuo. 
Por eso ha llegado a decir SS. Pío XI en la Encíclica Quadragésimo Anno "el socialismo, ya se considere como doctrina, ya como hecho histórico, ya como "Acción", si sigue siendo verdadero socialismo, aún después de sus concesiones a la verdad y a la justicia.... es incompatible con los dogmas de la Iglesia católica, ya que su manera de concebir la sociedad se opone diametralmente a la verdad cristiana".

En particular tratándose del comunismo, la Iglesia lo repudia clara y específicamente. Ya hemos visto que, inclusive por decreto de la Sagrada Congregación del Santo Oficio, se ha establecido que los que se adhieren a tal doctrina están de hecho sujetos a excomunión.

Repetidas veces desde 1849 se ha expresado la condenación de esto sistema, pero muy en especial en la Encíclica Divini Redemptoris de SS. Pío XI, de 19 de Marzo de 1937.

Las razones fundamentales que da para tal condena son que el co. munismo es ateo; que niega a la vida humana todo carácter espiritual; que se basa en el materialismo histórico; que favorece la lucha implacable de clases; que significa la desaparición de la propiedad privada y la privación total de la libertad para el hombre.

Así, dice el Pontífice: "La doctrina que el comunismo oculta bajo apariencias a veces tan seductoras, se funda hoy sobre los principios del materialismo dialéctico e histórico proclamado antes por Marx... Esta doc. trina enseña que no existe más que una sóla realidad: la materia con sas fuerzas ciegas, la cual por evolución, llega a ser planta, animal, hombre. La misma sociedad no es más que una apariencia y una forma de la materia que evoluciona del modo dicho, y que por ineludible necesidad tiende, en un perpétuo conflicto de fuerzas, hacia la síntesis tinal, una sociedad sin clases. Es evidente que en semejante doctrina no hay lugar para la idec de Dios, no existe ciferencia entre espíritu ni materia, ni entre cuerpo y alma; ni sobrevive el alma a la muerte, ni, por consiguiente, puede haber esperanza alguna de una vida futura".

"Insistiendo en el aspecto dialéctico de su materialismo, los comunistas sostienen que los hombres pueden acelerar el conflicto que ha de conducir el mundo hacia la síntesis final. De ahí sus esfuerzos por hacer más agudos los antagonismos que surgen entre las diversas clases de la sociedad; la lucha de clases, con sus odios y destrucciones, toma el aspecto de una cruzada por el progreso de la humanidad. En cambio, todas laj fuerzas, sean las que fueran, que resistan esas violencias sisiernáticas, deben ser aniquiladas como enemigas del género humano".

"El comunismo, además, despoja al hombre de su libertad, principio espiritual de su conducta moral: quita toda dignidad a la persona humana y todo treno moral contra el asalto de los estímulos ciegos. No reconoce al individuo, frente a la colectividad, ningún derecho natural de la persona humana, por ser ésta en la teoría comunista simple rueda engranada en el sistema... Ni concede a los individuos derecho alguno de propiedad sobre los bienes naturales y sobre los medios de producción... Niega la existencia de un vínculo matrimonial de naturaleza jurídico moral. En particular no existe para el comunismo nada que ligue a la mujer con la fami- 
lia y la casa... Niega finalmente a los padres el derecho a la educación...".

Es... "un sistema lleno de errores y sofismas, contrario a la razón y a las verdades de la revelación divina, subversivo del orden social, porqus equivale a la destrucción de sus bases fundamentales, desconocedor del verdaclero origen de la naturaleza y del fin del Estado, negador de los derechos de Ja persona humana, de su dignidad y libertad".

Igualmente ha reprobado la Iglesia otros regímenes totalitarios, como el facismo y el nacismo. Las encíclicas Non Abbiamo Bisogno de SS. Pío $\mathrm{XI}$ fechada en 29 de Junio de 1931 y Mit Brennender Sorge del mismo Pontífice, expedida el 14 de Marzo de 1937, son elocuentes expresiones al respecto.

"Una concepción que hace pertenecer al Estado las generaciones juveniles, enteramente y sin excepción, desde la edad primera hasta la edad adulta, - dice la primera - es inconciliable para un católico, con la verdadera doctrina católica; y no es menos inconciliable con el derecho natural de la familia; para un católico es inconciliable con la doctrina católica el pretender que la Iglesia, el Papa, deben limitarse a las prácticas exteriores de la religión (la misa y los sacramentos) y que todo lo restante de la educación pertenezca al Estado".

Si una raza o el pueblo, si el Estado o una forma determinada del mismo, si los representantes del poder estatal u otros elementos fundamentales de la sociedad humana tienen en el orden natural un puesto esencial y digno de respeto - dice la segunda-; con todo, quien los arranca de esta escala de valores terrenales elevándose a suprema norma de todo, aún de los valores religiosos, y, divinizánciolos con culto idolátrico, pervierte y falsifica el orden creado e impuesto por Dios, está lejos de la verdadera fé y de uncs concepción de la vida conforme ca ella'.

Nc es menos severa la Iglesia para censurar el Liberalismo primitivo, esto es el llamado liberalismo manchesteriano, igualmente ateo, basado en el individualismo, en una despiadada libre concurrencia sin freno alguno y que trataba al obrero como simple mercancía.

Dice por eso SS. Pío XI en su Encíclica Quadragésimo Anno, que el Liberalismo proponía un remedio que siendo mucho peor que el mismo mal, arrojaría a ia sociedad humana a mayores peligros".

Agrega también por ello refiriéndose a León XIII: sobrepasando audazmente los límites impuestos por el liberalismo (a la intervención del Estado), el Pontifice enseñó sin vacilaciones que (el Estacio) no puedo limitarso a ser mero guardián del derecho y clel recto orden, sino que debe trabajar con todo empeño para que "conforme a la naiuraleza y a la institución del Estado, florezca por medio de las leyes y de las insituciones la prosperidad tanto de la comunidad cuanto de los particulares".

No repudió sin embargo al liberalismo que reconozca a la divinidad y se desarrolle dentro cle cauces justos.

Dice SS. Pío XI en su encíclica Quxdragésimo Anno.

"Para evitar armbos escollos, el individualismo y el socialismo, debo sobre todo tenerse presente el doble carácter individual y social del capital $a$. de la propiedad y del trabajo". 
"Las relaciones que anudan el uno al otro deben ser reguladas por las leyes de una exactísima justicia conmutativa, apoyada en la cariciad cristiana".

"Es imprescindible que la libre concurrencia contenida dentro de ilmites razonables y justos, y, sobre todo el poder económico, estén sometidos efectivamente a la autoridad pública, en todo aquello que le está peculiarmente encomendado".

"Finalmente, las instituciones de los puebios deben acomodar la sociedad entera a las exigencias del bien común, es decir, a las reglas de la justicia social".

En cuanto al capitalismo. régimen basado en la propiedad privada de los bienes tanto de consumo cuanto de producción, lo censura también la Iglesia en cuanto persigue el lucro como objetivo primordial; y en cuantn se basa también en una libre concurrencia sin tasa ni medida, que permite el mal trato de los trabajadores, la destrucción de los débiles y de los pequeños, la formación de monopolios y la conquista de éstos por los oligopolios o poder supremo del dinero que domina a la sociedad y al Estacio; y cr.yos males se han agudizado particularmente en los tiernpos modemos".

Reconoce sin embargo la Iglesia que el capitalismo no es por su naturaleza vicioso, esto es en cuanto se basa en la existencia de ia propiedad privada de los bienes de consumo y de producción. Lo tacha por las deformaciones 0 vicios $a$ que está afecto.

Dijo a tal efecto SS. Pío XI en su encíclica Quadragésimo Anno:

"Lećn Xill puso todo empeño en ajustar esa organizcción económica a las normas del recto orden, de donde se deduce que no puede condenurse por sí misma. Y en realidad no es por su naturaleza viciosa; pero vioia el recto orcien cuando el capital esclaviza a los obreros o a la clase proletaria con tal fin y forma que los negocios $y$, por tanto, todo el capital sirvan a su voluntad y a su utilidad despreciando la dignidad humana de los obreros, la índole social de la economía y la misma justicia sccial $y$ bien común".

En esta situación, en que prácticamente la Iglesia rechaza varios de los sistemas sociales existentes en el mundo y pone graves reparos a los demás, es de preguntarse ¿cuál es la solución? y ha de responderse que la Iglesia ha señalado el remedio: poner en práctica los preceptos de la recta razón, esto es de la filosofía social cristiana.

Para ello los doctores de la Iglesia consideran que puede elegirse entre dos caminos: o bien reformar el capitalismo despojándolo de sus vicios; o crear un tercer sistema, ir más allá del capitalismo.

Ambas soluciones requieren sea la reforma de las estructuras socialos, sea el cambio de las mismas.

A muchos preocupa el uso de este término "estructuras sociales" o el que se diga que deben ser reformadas o cambiadas. Seguramente se recuerda que Marx sostiene que la producción determina la infra-estructura de la sociedad y que, según como ésta se encuentre organizada, en cada medio será la super-estructura, esto es la organización política y jurídica y 
a las cuales corresponden determinadas formas de la conciencia social, lo político, lo espiritual. la Iglesia.

Pero no hay que temer eso del empleo, del término "estructuras" por

Para ella dicho vocablo significa, sencillamente, "el funcionamiento de los ambientes en un sistema económico" (Encíclica Mater et Magistra),

pedir que sean reformadas si comprometen la dignidad humana, si entorpecen sistemáticamente el sentido de responsabilidad o si impiden la expresión de la iniciativa personal, no es nada amenazador ni contrario $\alpha$ la sana razón. Muy al revés, es simplemente señalar el medio de corregir los males sociales de la humanidad.

Mediante la reforma de estructuras puede sin duda causarse un mal incalculable e irreparable a la humanidad si tal reforma es llevada a cabo apresuradamente y en forma equivocada; pero en cambio, se le puede deparar un gran bien si se lleva a cabo en forma sensata y de acuerdo con las necesidades de la sociedad.

En tal sentido la reforma del capitalismo para quitarle sus vicics, o la adopción de una tercera solución "más allá del capitalismo" significaría. en todo caso: dar nuevo estímulo y quien sabe nuevas formas a la propieciad privada; y organizar el régimen del trabajo, de las remuneraciones, de las organizaciones sindicales y de solución de conflictos colectivos.

Significaría también reconocer la dignidad de la persona humana $y$ actuar de acuerdo con ello, en especial en cuanto concieme a los trabajadores, perfeccionar las relaciones entre los hombres y los poderes públicos en el seno de las distintas comunidades políticas, de las comunidades mis. mas entre sí y de todos con la comunidad mundial.

No pudiendo examinarse todos estos temas en una sola conferencia, corviene recordar a este respecto algunos puntos:

Tratándose de la propiedad privada la Iglesia considera que constituye un derecho natural del hombre. Por ello en vez de censurarla, alienta su extensión al mayor número, especialmente en la forma de pequeña y mediana propiedad, en modo tal que disminuyan los grandes desniveies económicos y sociales que actualmente prevalecen.

Se funda la Iglesia para aprobarla en que la propiedad privada completa la expansión de la persona humana, contribuye a su dignidad, alienta la vida y desarrollo de la familia y contribuye al bien común.

En lo que concierne al trabajo, reconoce la Iglesia que el esfuerzo del trabajador se hace sobre un capital; pero al mismo tiempo advierte que es un derecho fundamental del trabajador que en el ejercicio del mismo se le reconozca su dignidad humana.

Ve la Iglesia al trabajo como un instrumento del trabajador para subvenir $\alpha$ sus necesidades y a las de su familia, pero también considera que es para él un medio de disciplina y de perfección, y un instrumento de caridad y de goce humano que le permite colaborar al bien de la sociedad.

Refiriéndose a la remuneración del trabajador, la Iglesia busca que prevalezca la justicia y la caridad entendida en su sentido mós amplio.

Censura severísimamente el sistema que considera el trabajo como 
ura mercancía.

Condena también el sistema en que la empresa, con desmedro del trabajador, pone como fin último la utilidad sin tener en consideración el bien común.

No rechaza el régimen del salario, pero quiere que éste sea suficiente para subvenir a las necesidades del obrero y de su familia, que lo ponga al abrigo de los riesgos y que le permita hacer economias.

Claramente indica que el beneficio no puede ser exclusivamente para el empresario. Debe participar en el mismo el trabajador, sea considerándolo por anticipado en sus remuneraciones, sea viendo el medio de que participe en la liquidación de las mismas.

Áconseja, que, cuando sea posible, este sistema se suavice con el de la sociedad que permita al trabajador la participación en los beneficios. en el capital y aún en la gestión.

Pronunciándose sobre las asociaciones obreras, la Iglesia muy enfáticamente las favorece. Considera que el rico se puede defender por sí solo, pero que el obrero debe agruparse para tener vigor en su defensa.

En carta de la Sagrada Congregación del Concilio a Monseñor Lienart (1929) dice claramente:

1. La Iglesia reconoce y afirma el derecho de los patronos y obreros $\alpha$ constituir asociaciones sindicales, bien separadas, y vé en ellas un medio eficaz para la solución de la cuestión social. (sin lucha de clases).

2. La Iglesia en el estado actual de cosas, estima moralmente necesaria. la constitución de tales asociaciones sindicales.

3. La Iglesia exhorta a constituir tales asociaciones sindicales.

4. La Iglesja quiere que las asociaciones sindicales se establezcan y rijan según los principios de la fé y de la moral cristiana.

5. La lglesia quiere que estas asociaciones sindicales sean instrumentos de concordia y de paz y con ese fin sugiere la institución de comisiones mixtas como medio de unión entre ellas.

6. La Iglesia quiere que las asociaciones sindicales, suscitadas por los católicos para los católicos, se constituyan entre los católicos, sin desconocer, no obstante, que las necesidades particulares puedan obligar $a$ actuor en forma diferente.

En cuanto a los conflictos laborales, la Iglesia rechaza la lucha de clases, propicia las soluciones pacíficas y reconoce el derecho de huelga sólo en caso justificado.

Por ello favorece el establecimiento de un ambiente social y el desarollo de instituciones (comisiones mixtas - contactos permanentes) que tiendan hacer los conflictos poco posibles; $y$ también aconseja crear pro. cedimientos que permitan resolver pacíficamente los conflictos que estallen a pesar de todo.

Largo e imposible sería entrar en todo el detalle de cuanto puede hacerse según la Iglesia en materia social. Son las Encíclicas Pontíficias una 
admirable guía al respecto. Favorece ella la empresa artesana y la cooperativista, lo presencia activa del obrero en las empresas grandes y medias, y en todos los niveles, la difusión, como se ha licho de la pequeña y mediana propiedad, la reforma del medo agrario, la adecuación de los servi. cios públicos esenciales a tal medio, como caminos, transportes, comunicaciones, agua potable, habitación, asistencia sanitaria, instrucción, vida reiigiosa, medios recreativos, etc. Muy precisamente propicic los seguros sociales y sistemas de previsión social, la integración de los réditos agrícolas y una acción de propulsión y nivelación de las zonas desarrollatas.

Días enteros tomaría exponer en detalle tan amplia doctrina. Baste, por eso, concluir hoy diciendo que es una doctrina de paz y no de agresión.

"No en la revolución, dijo el Sumo Pontífice, en su alocución de 13 de Junio de 1943, sino en una solución concorde, está la salvación y la justicia. La violencia no ha hecho nunca otra cosa que destruir, no levantar; encender los pasiones, no calmarlas; acumular odios y ruinas, no hermanar a los contendientes; y ha precipitado a los hombres y a los paridos en la dura necesidad de reconstruir lentamente, tras de pruebas dolorosas, sobro los despojos de la discordia".

"Solo una evolución progresiva y prudente, valiente y conforme a la naturaleza, iluminada por las santas normas cristianas de justicia y de equiciad puede conducir a la sctisiacción de los deberes y de las necesidades del obrero".

Juan XXIII por eso, poco antes de morir, hizo su último llamado a los hombres y fué él un llamado de paz entre todos los pueblos, fundada sobre la verdad, la justicia, el amor fraterno y la libertad... Pacem in Te. rris... La dirigió no solo a los cristianos, sino también a todos los hombres de buena voluntad. No lo desoigamos. Es un legado invalorable del cural todos somos herederos. 